\title{
A promoção da atividade de estudo: repercussões para a organização do ensino
}

\author{
Cárita Portilho de Lima'; ${ }^{1}$ https://orcid.org/0000-0002-9386-4806 \\ Marie Claire Sekkel²; https://orcid.org/0000-0002-1575-9947
}

\begin{abstract}
Resumo
Com o intuito de contribuir para os debates relacionados à organização do ensino no contexto do ensino fundamental, este artigo apresenta uma análise teórica a respeito da atividade de estudo com vistas a nortear tanto a atividade de ensino como a intervenção do psicólogo escolar neste nível de ensino. A pertinência dessa discussão está vinculada à tese que a Educação deve assumir como um de seus princípios orientadores a promoção da atividade principal de cada período de vida dos estudantes. Esta tese baseia-se na concepção de que a atividade principal é aquela que possibilita as mudanças psicológicas essenciais na personalidade do sujeito em determinado período de sua vida e que, portanto, deve ser entendida como um critério para a organização de um ensino escolar que se aproxime de uma perspectiva humanizadora e emancipatória, pois passa a considerar as especificidades e necessidades de cada período do desenvolvimento humano como um dos fios condutores de suas ações.
\end{abstract}

Palavras-chave: Psicologia escolar; Psicologia Histórico-Cultural; Atividade Pedagógica.

\section{The promotion of the study activity: repercussions for the organization of education}

\begin{abstract}
In order to contribute to the debates related to the organization of teaching in the context of primary education, this article presents a theoretical analysis regarding the activity of study with a view to orienting both the teaching activity and the intervention of the school psychologist in this level of teaching. The pertinence of this discussion is linked to thesis that Education must assume as one of its guiding principles, the promotion of the main activity of each period of students life. This thesis is based on't the conception that the main activity is that which enables the essential psychological changes in the personality of the subject in a certain period of his life and that, therefore, should be understood as a criterion for the organization of a school teaching that is approached from a humanizing and emancipatory perspective, since it begins to consider the specificities and needs of each period of human development as one of the guiding threads of its actions.
\end{abstract}

Keywords: School psychology; Historical-Cultural Psychology; pedagogical activity.

\section{Promoción de la actividad de estudio: repercusiones para la organización de la enseñanza}

\begin{abstract}
Resumen desarrollo humano como uno de los hilos conductores de sus acciones.

Palabras clave: Psicología escolar; Psicología Histórico-Cultural; actividad pedagógica.

1 Universidade Federal da Paraíba - João Pessoa - PB - Brasil; carita.portilho@yahoo.com.br

2 Universidade de São Paulo - São Paulo - SP - Brasil; claire@sekkel.com
\end{abstract}

Con el objetivo de contribuir para los debates relacionados a la organización de la enseñanza en el contexto de la enseñanza primaria, en este artículo se presenta un análisis teórico a respeto de la actividad de estudio con objetivode nortear tanto la actividad de enseñanza como la intervención del psicólogo escolar en ese nivel de enseñanza. La pertinencia de esa discusión está vinculada a la tesis que la Educación debe asumir como uno de sus principios orientadores de la promoción de la actividad principal de cada período de vida de los estudiantes. Esta tesis se basa en la concepción de que la actividad principal es aquella que posibilita los cambios psicológicos esenciales en la personalidad del sujeto en determinado período de su vida y que, por lo tanto, debe ser entendida como un criterio para la organización de una enseñanza escolar que se acerque de una perspectiva de humanización y libertadora, pues pasa a considerar las especificidades y necesidades de cada período del 


\section{Introdução}

Como assevera Mendoza (2002), não é todo tipo de ensino que é igualmente efetivo em qualquer idade. Isto posto, o trabalho dos profissionais da Educação, dentre os quais inclui-se o psicólogo escolar, deverá assumir como fio condutor de suas ações a promoção da atividade principal dos estudantes, caso pretenda organizar um ensino que produza o desenvolvimento psíquico destes. Assumindo essa premissa como um dos elementos orientadores da organização do ensino, esse artigo pretende oferecer uma síntese conceitual a respeito da atividade de estudo, atividade principal dos estudantes no contexto do ensino fundamental. Diante disso, propomos como caminho argumentativo a análise e discussão de três temáticas essenciais para abordagem desse problema: a Teoria da Atividade e os conceitos de atividade principal e atividade de estudo.

\section{Uma introdução ao problema: a atividade humana}

Desde as elaborações iniciais de Vigotski, a atividade é apresentada como um princípio explicativo da consciência e do desenvolvimento das funções psicológicas superiores (Asbahr, 2011). Leontiev - psicólogo russo e um dos parceiros de Vigotski na construção da Psicologia Histórico-Cultural - direcionou seus estudos e pesquisas para a sistematização da Teoria da Atividade. O trabalho de compreensão da atividade como unidade de análise do desenvolvimento psíquico continuou a ser conduzido por outros pesquisadores russos que também assumiram o projeto de construção da Psicologia Histórico-Cultural. É importante ressaltar que a centralidade que a categoria atividade possui nessa teoria não é fortuita, mas, ao contrário, tal concepção está em consonância com a raiz teórico-metodológica na qual essa teoria assenta-se: o Materialismo Histórico Dialético. Em Marx (2004) encontramos claramente a defesa de que, para compreender o processo de humanização, é essencial analisar e explicar a atividade humana, definindo a vida em si como atividade, sendo que, nessa teoria, o trabalho - em sua dimensão ontológica e enquanto atividade humana - é entendido como categoria essencial para a explicação do processo de constituição histórica do homem.

Isso posto, torna-se importante explicitar como o conceito de atividade é apresentado por Leontiev (1981) em sua elaboração teórica. Para o autor, a atividade é um sistema que possui uma estrutura, passos internos e conversões, desenvolvimento. A atividade de um sujeito sempre é compreendida no sistema de relações da sociedade. Ou seja, na realização de sua atividade, o homem singular relaciona-se com o gênero humano a partir da mediação da sociedade. Além disso, a atividade é entendida como uma unidade mediada pelo psiquismo dos sujeitos e cuja função real é orientá-los no mundo dos objetos. Por fim, uma questão essencial sobre a sistematização teórica da categoria atividade desenvolvida por Leontiev (1978) diz respeito à compreen- são de que a atividade humana é sempre uma atividade objetal. Mas, o que viria a ser o objeto da atividade?

O objeto da atividade refere-se a uma determinada síntese entre uma materialidade empírica (uma forma sensorial do objeto) e uma materialidade histórica e social (o conjunto das relações sociais necessárias para se produzir e reproduzir as condições de vida em sociedade). A essa unidade, a esse conjunto de relações sociais (materiais e ideais) objetivadas pela prática social e que se apresentam como essenciais para um dado fenômeno é que estamos chamando de objeto da atividade. (Nascimento, 2014, p. 58).

A atividade possui como característica essencial a dimensão transformadora do homem sobre uma realidade material ou espiritual, sendo que a transformação da realidade produzirá, dialeticamente, a transformação do próprio homem. No que diz respeito à sua estrutura, a atividade humana pode ser analisada a partir das relações que se estabelecem entre necessidades e motivos, objetivos, condições e meios para executá-la, bem como das ações e operações que compõem a atividade (Davidov \& Slobódchikov, 1991).

Para Leontiev (1978), necessidade é o que dirige e regula a atividade concreta do sujeito em relação aos objetos. Segundo Davidov (1988), a atividade do sujeito sempre está ligada a certa necessidade. No entanto, uma necessidade por si mesma não é capaz de provocar nenhuma atividade de modo definido. Somente quando a necessidade encontra um objeto que corresponde a si mesma é que se torna possível a orientação e a regulação da atividade. O processo produzido a partir do encontro da necessidade e seu objeto de satisfação é nomeado como motivo da atividade. É importante destacar que os seres humanos possuem necessidades que não estão relacionadas apenas a garantia de sua existência biológica, mas, principalmente, sua existência cultural (Leontiev, 1978; Rigon, Asbahr, \& Moretti, 2010).

Os motivos possuem ainda o papel de direcionar as ações que compõem uma atividade. As ações consistem em componentes fundamentais da atividade (Leontiev, 1981), constituindo-se como processos subordinados a um objetivo consciente mediante os quais o resultado da atividade poderá ser alcançado, ou seja, as ações estão diretamente relacionadas com os objetivos da atividade e os motivos que regem as ações também estão direcionados aos motivos da atividade. Nesse sentido, a ação é um processo cujo motivo não coincide com seu objetivo, mas reside na atividade da qual ela faz parte (Leontiev, 1981). Dessa forma, para que a "ação surja e seja executada é necessário que seu objetivo apareça para o sujeito, em sua relação com o motivo da atividade da qual ela faz parte" (Leontiev, 1988, p. 69). Os objetivos para a atividade não são inventados arbitrariamente pelos sujeitos, mas estão dados dentro das circunstâncias objetivas da realidade, ou seja, ainda que o objetivo possa manifestar-se de forma abstraída da situação concreta da qual emerge, o objetivo não existe fora de uma situação objetal. Juntamente com o aspecto intencional que direciona a ação também devemos considerar a maneira a 
partir da qual o objetivo pode ser alcançado, como isso pode ocorrer, as condições objetivo-objetais para a consecução desse objetivo, seu aspecto operacional, o modo de execução dessa ação, pois uma ação pode ser executada por diferentes operações (assim como uma mesma operação pode relacionar-se a diferentes ações). Essa dimensão da atividade refere-se às operações que as compõe, às formas e métodos a partir dos quais as ações se realizam sendo que, mais cedo ou mais tarde, as ações irão se converter em funções mecânicas (Leontiev, 1981).

Assim, as atividades humanas, orientadas para a satisfação de necessidades, são impelidas por motivos que depois se desdobram em ações que, subordinadas a motivos conscientes, se objetivam a partir de operações possíveis relacionadas às condições para a realização dessa atividade e consecução de seu objetivo.

É importante destacar que a análise da estrutura da atividade deve ser articulada com a forma por meio da qual as relações internas entre seus componentes conformam o seu funcionamento, pois "a atividade comporta um processo que se caracteriza por apresentar transformações constantes" (Leontiev, 1981, p. 89).

Por fim, devemos destacar que para compreendermos a atividade humana desde essa perspectiva, é essencial considerarmos a unidade cognição-afeto (Vigotski, 2010), pois o psiquismo é entendido como um sistema interfuncional. Leontiev (1988) destaca que as emoções e sentimentos são um traço importante da atividade. Para Bozhovich (1976), uma adequada discussão sobre a atividade consciente do homem pressupõe considerarmos as necessidades e tendências do sujeito, suas vivências e seus processos psíquicos não conscientes, os afetos, pois, apenas por essa via, é possível superar uma análise intelectualizada da vida psíquica humana. Segundo Vigotski (2001), a unidade entre os processos afetivos e intelectuais permite descobrir o movimento direcional que parte das necessidades ou impulsos do indivíduo e que direciona a dinâmica do comportamento e da atividade concreta da personalidade. Além disso, o autor defende que as emoções possuem um caráter organizador em relação ao comportamento humano, elas excitam, estimulam ou inibem nossas ações, pois "toda emoção é um chamamento à ação ou uma renúncia a ela" (Vigotski, 2004, p. 139), ou seja, a dimensão afetiva é essencial para a compreensão da atividade humana.

\section{Compreendendo o conceito de atividade principal}

A Psicologia Histórico-Cultural considera que para assumir efetivamente o intuito de promover o desenvolvimento dos estudantes a Educação precisa levar em conta as peculiaridades e as leis de cada período do desenvolvimento humano, bem como suas relações com as particularidades do processo educativo.

Para Vigotski (2006), os diferentes momentos da vida são orientados por diferentes forças motrizes (necessidades, interesses e aspirações que o sujeito constrói em sua relação com a realidade) que, ao se transformarem, reverberam na conduta dos sujeitos, em sua atividade e em suas relações. Nesse sentido, para que a escola assuma sua função de promoção do desenvolvimento humano é essencial que ela considere as especificidades contidas nos diferentes períodos que compõem esse processo, sem perder de vista sua articulação com as relações sociais às quais os sujeitos estão inseridos.

Falar sobre a centralidade das relações sociais para o desenvolvimento humano significa reconhecer que as condições históricas concretas determinam o conteúdo concreto de cada período do desenvolvimento e também sobre o desenvolvimento humano como um todo (Leontiev, 1988).

Assim, para conseguir compreender as especificidades de cada período do desenvolvimento humano, a Psicologia Histórico-Cultural propõe uma análise do desenvolvimento humano a partir da periodização desse processo. Para Elkonin (1987), o problema da periodização do desenvolvimento humano possui grande importância teórica, pois, como já foi dito, as forças motrizes variam em cada período do desenvolvimento e conhecê-las torna-se importante quando se pretende organizar processos pedagógicos que assumam suas finalidades humanizadoras.

A discussão sobre a periodização do desenvolvimento humano é organizada a partir do conceito de atividade principal. A atividade principal é a atividade que promove as principais mudanças psicológicas na personalidade do sujeito em determinado período de sua vida sendo, portanto, a atividade por meio da qual os processos psíquicos tomam forma e são reorganizados (Leontiev, 1988).

Dessa forma, a atividade principal é aquela que rege, direciona, guia e possui importância fundamental para o desenvolvimento da personalidade do sujeito. Além disso, é a mudança da atividade principal que determina a mudança de um período para outro no desenvolvimento do sujeito, considerando a relação que ele constrói com a realidade (Elkonin, 1987; Davidov, 1988).

No que tange às atividades principais nos diferentes momentos do desenvolvimento infantil Elkonin ${ }^{1}$ (1987) propõe a seguinte periodização: comunicação emocional direta, atividade objetal-manipulatória, brincadeira de papeis, atividade de estudo, comunicação íntima pessoal e atividade de estudo e profissional.

Estudar a periodização do desenvolvimento humano de modo que se potencializem os processos pedagógicos requer compreender que todos os períodos do desenvolvimento guardam relação entre si. Dessa forma, considerar a periodização como orientadora da prática pedagógica e psicológica demanda conhecer como se deu o processo de desenvolvimento do estudante até o presente momento de sua escolarização, pois essa análise é essencial para avaliar o desenvolvimento atual e também para planejar como se deve conduzir o seu desenvolvimento futuro, o que significa reafirmar que não basta identificar os processos já desenvolvidos pelo sujeito, também é necessário compreender os

1 Na periodização proposta por Davidov (1988) a atividade de comunicação íntima pessoal é substituída pela atividade socialmente útil. 
processos que estão em maturação (Vigotski, 2006). Além disso, segundo Elkonin (1987) o surgimento e conversão em atividade principal não eliminam as atividades anteriores, pois a vida dos sujeitos é multifacetada e as atividades são variadas. O que acontece é apenas a mudança no que diz respeito ao lugar que cada atividade assume na vida de uma pessoa, considerando os impactos da atividade no desenvolvimento de sua personalidade e na sua relação com a realidade.

\section{A atividade de estudo e o aprender a estudar}

A discussão a respeito da atividade de estudo será iniciada a partir de uma breve apresentação de algumas questões relativas à brincadeira de papeis, pois, como exposto, não é possível compreendermos a periodização do desenvolvimento humano se analisarmos isoladamente as atividades objetivadas pelos sujeitos.

Para Elkonin (1987), a brincadeira de papeis é uma atividade social por essência, tem uma origem histórica, um conteúdo social e possui uma importância múltipla no desenvolvimento psíquico das crianças. Na perspectiva do autor, podemos assim sintetizar a principal contribuição dessa atividade para o desenvolvimento infantil:

...graças a procedimentos peculiares (a assunção, pela criança, ao papel de pessoa adulta e suas funções sóciolaborais, o caráter representativo generalizado da reprodução das ações objetais, a transferência dos significados de um objeto a outro, etc.), a criança modela no jogo as relações com as pessoas. (Elkonin, 1987, p. 118).

Dessa forma, a brincadeira é uma atividade que contribui para o desenvolvimento da capacidade de modelação, tão importante na atividade de estudo. Além disso, a brincadeira de papeis faz emergir na criança o desejo de desenvolver uma atividade socialmente significativa e valorizada, aspiração que, segundo Elkonin (1987), constitui o principal momento de sua preparação para a aprendizagem escolar.

Outra contribuição da brincadeira para a aprendizagem escolar posterior reside no fato de que, por meio das regras da brincadeira de papeis sociais as crianças começam o exercício da autodisciplina que será tão fundamental ao processo de aprendizagem e, consequentemente, de desenvolvimento no momento da atividade de estudo (Marcolino \& Mello, 2015).

O impacto da brincadeira no desenvolvimento do pensamento simbólico e na imaginação da criança é outro ponto que importa para nossa discussão, pois como explica Davidov (1988) essas capacidades estão estreitamente vinculadas à constituição da necessidade de estudar. Para Marcolino e Mello (2015):

O envolvimento de objetos para substituir outros ausentes e necessários à brincadeira e ao papel - o que exige a separação entre o campo real (óptico) e o campo do sentido (imaginário) - constitui na criança a função simbólica da consciência... Mais tarde, a função psíquica será também essencial no processo de apropriação da cultura escrita, instrumento cultural complexo que se apresenta como uma representação de segunda ordem e, por isso, sua apropriação é condicionada à formação dessa função psíquica superior na criança. (p. 460).

Por fim, é importante citar a importância da brincadeira para que a criança se reconheça e se situe no contexto em que vive e para que crie bases para sua articulação nos coletivos dos quais faz parte. Para Sekkel:

O brincar, ao possibilitar a transposição de barreiras, permite imaginar o lugar do outro (polícia, ladrão, lobo mau, superheróis etc.), criando identificações. É possível relacionar, a partir desses elementos, a brincadeira e o desenvolvimento da compaixão que, como disse anteriormente, nos coloca lado a lado na construção de uma sociedade mais sensível às necessidades humanas. (Sekkel, 2003, p. 201).

Feita essa breve apresentação é possível passarmos para a discussão a respeito da atividade de estudo. $A$ atividade de estudo é definida como uma via a partir da qual os estudantes podem se apropriar, ativamente, dos conhecimentos escolares e ao estabelecer uma relação com a atividade de ensino compõe uma unidade dialética que nomeamos como atividade pedagógica (Bernardes, 2012).

Para Davidov e Slobódchikov (1991), a atividade de estudo precisa conter todos os componentes relacionados à atividade, ou seja, necessidade, motivo, ações, operações, objetivos e também um objeto. A discussão a respeito do objeto de uma atividade é importante, pois é justamente essa dimensão que irá diferenciar uma atividade de outra. No caso da atividade de estudo, defendemos que seu objeto é o conhecimento escolar. O conhecimento escolar constitui-se como uma síntese dos conhecimentos, capacidades e experiências socialmente elaboradas pela humanidade que estão vinculados aos conhecimentos científicos, artísticos, filosóficos, políticos, morais, esportivos, entre outros.

Uma dimensão essencial da atividade de estudo a ser enfatizada diz respeito ao caráter ativo que o estudante assume nesse processo. Para Vigotski (2010), a experiência pessoal do estudante é a base principal do trabalho pedagógico. Na perspectiva desse autor, o processo pedagógico gira em torno da ideia de que não se pode educar o outro diretamente e que, portanto, a Educação deve ser organizada de tal forma que o próprio estudante se eduque. É essencial esclarecer que essa compreensão não incorre na diminuição da importância da ação do professor na aprendizagem do estudante, mas exatamente o contrário. Segundo Vigotski (2010), o professor é o organizador do meio educativo que oferecerá as experiências necessárias para a aprendizagem. Para o autor, o processo educacional deve ser "trilateralmente ativo", pois estudante, professor e o meio pedagógico criado pelo professor devem ser ativos. 
Dito isso, é necessário destacar que não é toda ação desenvolvida pelo estudante no contexto da escola que pode ser vinculada à atividade de estudo. Se não for possível evidenciar e definir o conteúdo dos componentes da atividade, se não houver uma transformação real pela criança da atividade e de si mesma, o termo atividade não poderá ser usado (Davidov, 1999). Dessa forma, quando os estudantes se apropriam de certos conhecimentos de forma passiva, por exemplo, a atividade de estudo, na perspectiva apresentada, não se efetivou ou está sendo realizada de forma incompleta - o que não significa dizer que não houve um processo de aprendizado.

Assim, o princípio ativo, criativo e transformador da atividade de estudo configura-se como uma questão central. Sobre isso temos que:

$\mathrm{Na}$ transformação experimental do material de estudo existe, inevitavelmente, um momento criador: o caráter ativo da assimilação dos conhecimentos que se referem ao objeto de experimentação. Ali onde o professor cria sistematicamente as condições que requerem dos alunos a obtenção dos conhecimentos acerca do objeto por meio da experimentação, ali as crianças se enfrentam com tarefas que exigem a realização da atividade de estudo. (Davidov \& Slobódchikov, 1991).

Isso posto, é possível destacar que, para que a atividade de estudo seja objetivada dentro da sala de aula, o ensino precisa ser intencional e conscientemente organizado com essa finalidade, ou seja, promover a atividade do estudante, o que requer a ação de todos os profissionais da Educação, incluindo o psicólogo escolar.

A necessidade de que o ensino tenha como premissa promover a atividade de estudo é discutida por Asbahr (2011). Em sua tese de doutorado a autora analisa os profundos limites que a atual organização do ensino das escolas públicas brasileiras impõe à formação da atividade de estudo eaponta que, contraditoriamente, as relações escolares também indicam possibilidades de formação dessa atividade. Ou seja, para a autora, as contradições escolares apresentam possibilidades, mesmo que incipientes, para a constituição da atividade de estudo, ainda que as condições hegemonicamente impostas à atividade humana em nossa sociedade sejam alienantes. Diante disso, problematizamos: considerando a forma corrompida e fragmentada, por meio da qual as relações sociais são constituídas no modo de produção capitalista e as determinações desse processo na organização da atividade humana, como podemos construir e/ou fortalecer meios para a realização da atividade humana a partir de funcionamentos mais conscientes, integrados e humanizadores? Como criar e assegurar possibilidades de efetivação da atividade de estudo levando em conta a forma por meio da qual temos organizado nossas escolas? Ou seja, como favorecer a organização de uma escola que, ao assumir efetivamente sua função de socializar os conhecimentos historicamente acumulados pela humanidade, possa produzir a atividade de ensino e estudo e constituir-se como um movimento de resistência à reprodução de modos de organização social marcadamente desiguais e excludentes?

Uma importante via de problematização sobre a contradição que atravessa a atividade humana nessa organização social pode ser encontrada na própria argumentação de Asbahr (2011): a atividade como princípio explicativo do desenvolvimento psíquico, deve ser considerada em suas duas dimensões inerentes, a dimensão universal da atividade - em sua condição de humanização - e sua dimensão particular de efetivação na sociedade capitalista - hegemonicamente (re)produtora da alienação.

Diante disso, este trabalho incorpora-se ao movimento que busca construir - de forma consciente e coletiva possibilidades a partir das quais a escola - ao considerar os múltiplos determinantes históricos, sociais, políticos e econômicos que a atravessam - consiga efetivar o desenvolvimento da atividade de estudo pelo estudante em sua rotina do trabalho. Dessa forma, aproximamo-nos do posicionamento defendido por Löwy (1997) de que para a construção de uma práxis revolucionária (baseada no marxismo crítico) é preciso garantir a coincidência da mudança das circunstâncias e a transformação das consciências. Ou seja, não podemos esperar que ocorram mudanças na forma de organização e produção da vida em sociedade para que, depois, possamos pensar uma escola coerente com outro projeto social que forme consciências revolucionárias. Mas, ao contrário, é preciso pensar em como organizar uma escola na qual a atividade de ensino e a atividade de estudo possam se efetivar e buscar vias de construção de consciências mais coletivistas que construam possibilidades de problematização, enfrentamento e transformação das condições concretas socialmente instituídas. Assim, coadunamos com Davidov (1988) ao apostarmos na potencialidade criadora dos sujeitos para construir novas formas de vida social, intervindo nas escolas que temos e impulsionando-as dialeticamente na direção dos objetivos emancipatórios, pois como assevera Saviani (2002) educar tendo em vista as finalidades defendidas por uma perspectiva marxista de Educação exigiria instituições educacionais diferentes daquelas que possuímos, mas não nos é possível criar novas instituições independentemente das atuais.

Diante disso, defendemos que para caminharmos no sentido de alcançar esse propósito é essencial que esse processo seja vivido como um desafio coletivo por parte dos professores, pelos demais profissionais da escola (entre os quais devemos incluir o psicólogo) e também pelos estudantes e suas famílias. Nesse sentido, é essencial destacarmos a dimensão coletiva que o ensino e estudo também precisam assumir nesse processo.Enfatizar a dimensão coletiva inerente ao processo de organização do ensino e do estudo desde essa perspectiva não exclui a preocupação com as questões pessoais e singulares de cada estudante, mas ao contrário. Para Davidov e Márkova (1987), nas condições de ensino dirigido, as diferenças individuais não se atenuam, mas, tornam-se mais evidentes e permitem orientar de forma mais particular a atividade de estudo de cada estudante, pois o professor consegue ter elementos que o ajudam a 
avaliar em que momento do processo de constituição da atividade de estudo encontra-se cada um dos estudantes. Assim, a defesa de um ensino que busque consciente e intencionalmente promover a atividade de estudo, a partir da atividade de ensino, considerando as dimensões coletivas desse processo, não abstrai de seu campo de debate as singularidades apresentadas pelos sujeitos envolvidos no processo, mas ao contrário, apresenta critérios e indicadores claros de acompanhamento do processo de escolarização de cada estudante.

Ao trazermos para o centro do debate a importância de compreendermos as especificidades dos estudantes e seu momento de constituição da atividade de estudo, começamos a nos aproximar de outra dimensão importante para a promoção da atividade de estudo, que diz respeito ao fato de que cada estudante precisa experimentar uma necessidade e uma motivação que o leve a engajar-se nessa atividade.

As necessidades e os motivos possuem papel essencial na atividade de estudo, pois é o ponto de partida que orienta os estudantes na obtenção de conhecimentos escolares, como resultado de sua própria atividade transformadora de estudo. Para Davidov e Slobódchikov (1991) a necessidade de estudo:

...é a necessidade do escolar de experimentar real ou mentalmente um ou outro objeto, com o fim de separar nele os aspectos gerais essenciais e particulares externos e suas interrelações. Assinalemos que em lógica se chamam "teóricos" os conhecimentos da interrelação do essencial e o particular.

No que diz respeito aos motivos para a atividade de estudo é importante mencionar que eles podem ser divididos em duas grandes categorias: os motivos que estão relacionados diretamente ao conhecimento e os motivos que correspondentes às relações entre a criança e seu meio social - sendo ambos essenciais para que o estudante desenvolva com êxito a atividade de estudo (Bozhovich, 1972). Como já foi dito na seção anterior, é essencial considerarmos que os motivos para uma atividade não existem a priori, mas precisam ser constituídos nas e por meio das relações sociais nas e a partir das quais os sujeitos se desenvolvem. No caso da atividade de estudo, os motivos precisam se constituir durante a própria trajetória escolar do estudante, na relação que esse sujeito estabelece consigo mesmo, com os pares, profissionais da Educação e familiares. Essa concepção opõe-se, claramente, ao lugar comum tão disseminado na Educação de que os estudantes são ou não são naturalmente interessados pelos conhecimentos escolares e motivados a apreendê-los. Além disso, é importante destacar que, quando se trata de uma criança pequena, as necessidades e motivos para qualquer atividade se constituem a partir da colaboração do adulto, pois conforme esclarecem Bozhovich e Blagonadiezhina (1972) é o apoio do adulto que oferece motivação suplementar para que a criança conclua sua atividade e supere seu desejo de abandoná-la.
Dito isso é possível explicitar as razões que nos levam a defender a atividade de estudo como uma via potente para a promoção do desenvolvimento psíquico dos estudantes. Para a Psicologia Histórico-Cultural é por meio dessa atividade que se pode alcançar uma aprendizagem mais consciente e intencional. Nessa teoria, aprendizagem e desenvolvimento são processos distintos, mas guardam uma profunda relação, pois a aprendizagem bem organizada resulta no desenvolvimento psíquico dos sujeitos. Para Davidov e Márkova (1987):

O desenvolvimento se realiza através da assimilação (apropriação) pelo indivíduo da experiência históricosocial... Os avanços no desenvolvimento psíquico, por sua vez, servem de premissa para a assimilação de novos conhecimentos e habilidades de conteúdo mais complexo. Mas, a assimilação nem sempre conduz ao desenvolvimento... ao afirmar a influência da assimilação sobre o desenvolvimento se deve tomar em conta também a lógica do próprio desenvolvimento..., as particularidades psicofisiológicas da criança que, segundo nosso ponto de vista, desde o primeiro dia de vida são mediatizadas pelo meio social e já nesta forma mediatizada exercem uma ou outra influência no desenvolvimento psíquico. (pp. 321-322).

Com o intuito de evidenciar empiricamente os efeitos da aprendizagem no desenvolvimento humano, pesquisadores da Psicologia Histórico-Cultural propuseram estudos organizados a partir do método do experimento formativo (Davidov, 1986). No experimento formativo, o pesquisador possui uma intervenção ativa ao produzir os processos psicológicos que pretende estudar. Para a realização desse experimento, é necessário que se conduza a formação desses processos nas crianças a partir de meios psicológicos e pedagógicos. A partir dessas pesquisas, os psicólogos soviéticos puderam comprovar como a aprendizagem impulsiona o desenvolvimento das crianças e tiveram a possibilidade de estudar ainda as condições e leis de origem dessas novas formações psicológicas.

Ainda no que diz respeito à relação entre aprendizagem e desenvolvimento é importante dizer que a passagem da aprendizagem para o desenvolvimento não é um processo simples e nem está completamente explicado pela Psicologia Histórico-Cultural.

Com vistas à promoção da aprendizagem dos estudantes por meio da atividade de estudo é necessário que o ensino seja organizado por meio das tarefas de estudo. Para Davidov e Márkova (1987) a tarefa de estudo é a unidade fundamental da atividade de estudo, sua unidade de análise. Os autores entendem por tarefa de estudo a unidade entre o objetivo da ação de estudo e as condições para alcançá-lo. As tarefas de estudo apresentam-se ao estudante como uma via para resolução de alguma situação-problema e que, para ser solucionada, exigirá determinadas situações de estudo (Davidov, 1988).

A realização das tarefas de estudo possui importância fundamental para a constituição das necessidades relacio- 
nadas à atividade de estudo, pois trata-se de um processo inicial a partir do qual, ao se apropriar dos conhecimentos escolares, os estudantes passam a experimentar pessoalmente a importância desse processo para a sua aprendizagem e desenvolvimento (Davidov \& Márkova, 1987).

A principal diferença da tarefa de estudo das outras tarefas consiste em que sua finalidade e resultado é a transformação do próprio sujeito atuante, a constituição de neoformações psicológicas, e não na transformação das coisas sobre as quais atua o sujeito ou que atuam sobre ele (Davidov \& Márkova, 1987). O resultado da atividade de estudo, no curso da qual ocorre a assimilação de conceitos científicos é, antes de tudo, a transformação do próprio estudante, a promoção de seu desenvolvimento. Nesse ponto é fundamental destacar que, a busca pela efetivação da atividade de estudo não deve restringir-se apenas a dimensão intelectual do estudante e de seu desenvolvimento, mas sim considerar outras características que compõem esse processo, como as afetivas, volitivas e motivacionais, buscando realizar tarefas de estudo que conduzam ao desenvolvimento integral dos estudantes.

A partir da perspectiva da Psicologia Histórico-Cultural, as tarefas de estudo devem exigir que os estudantes analisem as condições de origem dos conhecimentos e dominem os procedimentos correspondentes para a sua obtenção (Davidov \& Márkova, 1987). Na concepção de Davidov e Slobódchikov (1991) a tarefa de estudo requer a experimentação do material de estudo, sua transformação e, portanto, constitui-se como etapa fundamental para a efetivação da atividade de estudo.

Dessa forma, podemos concluir que a tarefa de estudo está necessariamente ligada ao contexto escolar, essencialmente à ação do professor. No entanto, tal tarefa precisa encontrar um estudante motivado a realizá-la. E, nesse sentido, importa lembrar que as necessidades que desencadeiam os motivos para a atividade de estudo também são constituídas socialmente, ou seja, no contexto escolar, familiar, comunitário, entre outros.

Entendendo as tarefas de estudo como componentes importantes para a efetivação da atividade de estudo apresentamos algumas ações a serem consideradas para a organização dessa tarefa: 1) é necessário que a solução da tarefa exija do estudante a construção de procedimentos até então desconhecidos para ele (aqui fica explícito o caráter de transformação nessa tarefa), sendo que a construção desses procedimentos está relacionada tanto ao caráter geral como ao caráter particular da tarefa; 2) a construção dos procedimentos desenvolvidos a partir da tarefa de estudo deve culminar em uma modelação em forma material, gráfica ou semântica da relação ou fenômeno estudado e; por fim, 3) a execução da tarefa deve envolver o controle e avaliação da ação de estudo pelo próprio estudante - o controle permite ao estudante assegurar-se de que executou todas as ações de estudo e a avaliação permite determinar se assimilou (em que medida) ou não a solução geral da tarefa de estudo dada (Davidov \& Slobódchikov, 1991).
Inserida na discussão sobre a organização das tarefas de estudo também está a reflexão a respeito do conteúdo das ações que compõem as tarefas. Diante disso, destacamos que o conteúdo das ações deve estar relacionado à formação e desenvolvimento do pensamento teórico (dialético) nos estudantes de todos os níveis de ensino. Para Davidov e Slobódchikov (1991) disso depende a possibilidade de que os estudantes desenvolvam suas capacidades criativas, a atividade, a autonomia, ou seja, sua personalidade.

Outro elemento que precisa ser analisado dentro da discussão sobre a tarefa de estudo e formação do pensamento teórico é a questão da modelação. Esse processo está relacionado à segunda ação descrita por Davidov e Slobódchikov (1991) e compõe o processo de análise que envolve uma tarefa de estudo. A modelação consiste em construir mentalmente ou em forma material, um sistema que reproduza as relações essenciais do fenômeno estudado/investigado. Os modelos são ferramentas que explicitam o movimento do pensamento (nesse caso do estudante que está se apropriando dos conhecimentos escolares) em busca dos nexos que constituem o objeto estudado, da explicitação de suas leis gerais. Existe um complexo caminho a ser apropriado pelo estudante até que ele consiga desenvolver modelos que atendam as premissas apresentadas. Identificamos como início desse processo os momentos nos quais as crianças modelam objetos em uma massinha de modelar ou quando, por meio da brincadeira de papeis, a criança começa a modelar as relações sociais. Para a Psicologia Histórico-Cultural, os modelos são instrumentos essenciais para conduzir a criança no processo de interiorização dos conhecimentos estudados e apropriação dos procedimentos relacionados às análises necessárias para compreensão de algum objeto ou fenômeno (Elkonin, 1987; Bozhovich, 1976). Dessa forma, os modelos constituem-se como mediadores externos do processo de apropriação por parte dos estudantes dos conhecimentos teóricos. Além disso, Elkonin (1987) e Bozhovich (1976) atribuem grande importância aos modelos no processo de apropriação da criança das tarefas, motivos e normas de uma atividade social. Para Elkonin (1987), é por meio da reprodução ou modelação que a criança, em relação com os adultos, comunidades, grupos e coletivos consegue objetivar ações que vão conduzi-la à apropriação e formação de uma atividade.

Dessa forma, explicita-se uma das vias a partir da qual a atividade de estudo relaciona-se ao desenvolvimento do pensamento teórico dos estudantes. No entanto, assim como a aprendizagem pode ocorrer sem a atividade de estudo, o pensamento teórico também pode se desenvolver em estudantes inseridos em instituições escolares nas quais a promoção da atividade de estudo não é a perspectiva central que orienta a organização do ensino. No entanto, a consciência e o pensamento teórico formam-se de maneira espontânea e não em todos os estudantes (Davidov \& Slobódchikov, 1991), o que podemos facilmente observar em nossas escolas. Ou seja, uma escola que não se organiza de modo a promover intencionalmente a atividade de estudo para todos os estudantes, está atuando intensamente no 
sentido de favorecer a produção do fracasso escolar, pois o engajamento na atividade de estudo, a apropriação do conhecimento e, portanto, o desenvolvimento psíquico não será assegurado a todos os estudantes.

Por fim, é importante apresentarmos a estrutura da atividade de estudo proposta por Davidov e Márkova (1987). Para os autores essa atividade comporta: 1) a compreensão pelo estudante de que a realização da tarefa de estudo está estreitamente ligada à apropriação das generalizações teóricas produzidas no campo da ciência; 2) a busca por uma realização autônoma da atividade de estudo considerando a motivação do estudo e a transformação do estudante em sujeito da atividade; 3) a realização pelo estudante das ações de estudos e 4) a realização pelo estudante de ações de controle e avaliação. Todos esses aspectos do estudo formam-se, inicialmente, em atividade conjunta com o professor e demais estudantes para depois ir se encaminhando em conquistas individuais de cada um dos estudantes.

Ao explicitarmos o caráter coletivo da atividade de estudo evidenciamos fortemente o papel do professor nesse processo. As ações pertinentes ao professor para dirigir a atividade de estudo podem ser assim sintetizadas: 1) elaborar junto ao estudante cada componente da atividade de estudo; 2) aperfeiçoar os aspectos motivacionais e operacionais do estudo; 3) colaborar na transformação do estudante em sujeito da atividade de estudo por ele realizada; 4) favorecer o domínio, por parte do estudante, das formas de atividade de estudo conjuntas; além disso, 5) avaliar o desenvolvimento do estudante como efeito da atividade de estudo (Davidov \& Márkova, 1987).

Dessa forma, podemos compreender, a partir das discussões expostas até o momento, que em oposição à máxima do "aprender a aprender" tão fortemente divulgada pelo Construtivismo no campo educacional (Duarte, 2001), a Psicologia Histórico-Cultural defende que o ensino deve ser intencional e conscientemente organizado de modo que o estudante, possa "aprender a estudar", pois essa capacidade não é algo intrínseco a ele, é preciso ensiná-lo a estudar, para que com isso o estudante possa se apropriar das experiências histórico-sociais e obter como produto a aprendizagem e o desenvolvimento de seu psiquismo. Assim, ao contrário do Construtivismo, a Psicologia Histórico-Cultural resgata a centralidade dos conteúdos escolares nas relações pedagógicas.

Nesse sentido, explicitamos o posicionamento de que é função social da escola mediar os conhecimentos científicos, artísticos, filosóficos, políticos, morais, esportivos, entre outros, constituídos historicamente pela humanidade, defendendo que, em uma sociedade organizada em classes sociais antagônicas, a escola deve buscar garantir uma organização que possibilite a apropriação desse conhecimento à maior parte da população e buscar construir barreiras à reprodução da lógica capitalista no interior das instituições escolares, como já explicitado.
Tendo apresentado a análise teórica sobre a atividade de estudo resta-nos retomara tese de que a organização do ensino deve assumir como um de seus pressupostos a promoção da atividade principal dos estudantes. Dessa forma, defendemos que, no contexto do ensino fundamental, o trabalho dos profissionais da Educação, dentre os quais se encontram professores e psicólogos escolares, deve assumir como princípio orientador a promoção da atividade de estudo. Como foi explicado no decorrer da argumentação, essa defesa sustenta-se na compreensão de que a atividade principal é essencial para a produção dos saltos qualitativos necessários para o desenvolvimento dos seres humanos nos diferentes momentos de sua vida. Nesse sentido, entende-se que para que a escola construa condições concretas de assumir sua função humanizadora é essencial que as necessidades específicas de cada período do desenvolvimento humano sejam assumidas como orientadoras da prática pedagógica e também da prática psicológica. Dessa forma, a promoção da atividade de estudo, entendida como a atividade principal dos estudantes que frequentam o ensino fundamental, deve ser tomada como fio condutor da atuação dos profissionais da Educação nesse contexto.

\section{Referências}

Asbahr, F. S. S. (2011). "Por que aprender isso, professora?" Sentido pessoal e atividade de estudo na Psicologia Histórico-Cultural. Tese de Doutorado, Instituto de Psicologia, Universidade de São Paulo, São Paulo.

Bernardes, M. E. M. (2012). Mediações simbólicas na atividade pedagógica: contribuições da teoria histórico-cultural para o ensino e aprendizagem. Curitiba: CRV.

Bozhovich, L. I. (1972). El problema del desarrollo de la esfera de motivaciones del niño. In: Bozhovich,L. I. (Org.). Estudios de las motivaciones de la conducta de los niños y adolescentes. (pp. 5-62). La Habana: Editorial Pueblo y Educación.

Bozhovich, L. I. (1976). La personalidad y su formación en la edad infantil: investigaciones psicológicas. Havana: Editorial Pueblo y Educación.

Bozhovich, L. I.; Blagonadiezhina, L. (1972). Prefacio. In: Bozhovich,L. I.(Org.), Estudios de las motivaciones de la conducta de los niños y adolescentes. Habana: Editorial Pueblo y Educación.

Davidov, V. V. (1986). Problemas do ensino desenvolvimental - A Experiência da Pesquisa Teórica e Experimental na Psicologia (J. C. Libâneo; R. A. M. M. Freitas, Trads.). Revista Soviet Education, 30(8), 46-102.

Davidov, V. V. (1988). La enseñanza escolar y el desarrollo psíquico: investigación teórica y experimental. Moscou: Editorial Progreso.

Davidov, V. V. (1999). O que é atividade de estudo (E. Prestes, trad.).

\section{Considerações Finais}


Revista Escola inicial, (7), 1-9.

Davidov, V. V.; Márkova, A. (1987). La concepcion de la actividad de estudio de los escolares. In: Davidov, V.; Shuare, M. (Orgs.), La psicología evolutiva y pedagogía en la URSS: antología. (pp. 316337). Moscou: Progreso.

Davidov, V. V.; Slobódchikov, V. I. (1991). La enseñanza que desarrolla en la escuela del desarrollo. In: Múdrik A. B. (Org.), La educación y la enseñanza: una mirada al futuro (pp. 118-144). Moscú: Ed. Progreso.

Duarte, N. (2001). As pedagogias do aprender a aprender e algunas ilusões da assim chamada sociedade do conhecimento. Revista Brasileira de Educação, (18), 35-40.

Elkonin, D. B. (1987). Sobre el problema de la periodización del desarrollo psíquico en la infancia. In: Davidov, V.; Shuare, M. (Orgs.), La psicología evolutiva y pedagogía en URSS: antología. (pp. 104-124). Moscou: Editorial Progreso.

Leontiev, A. N. (1978). O desenvolvimento do psiquismo. Lisboa: Livros Horizonte.

Leontiev, A. N. (1981). Actividad, Conciencia y Personalidad. Havana: Editorial Pueblo y Educación.

Leontiev, A. N. (1988). Uma contribuição à teoria do desenvolvimento da psique infantil. In: Vigotski, L. S.; Luria, A. R.; Leontiev, A. N., Linguagem, desenvolvimento e aprendizagem (pp. 59-83). São Paulo: Ed. Ícone.

Löwy, M. (1997). Pour un marxisme critique (J. C. Leite, trad.). In: Marx après les marxismes. Paris: Editora L'Harmattan.

Marcolino, S.; Mello, S. A. (2015). Temas das Brincadeiras de Papéis na Educação Infantil. Psicologia: ciência e profissão, 35(2), 457472.
Marx, K. (2004). Manuscritos econômico-filosóficos (J. Ranieri, trad.) São Paulo: Boitempo.

Mendoza, F. M. (2002). La educación y el desarrollo. In: Mendoza, F. M. (Org.), La atención clínico-educativa en la edad preescolar. Habana: Editorial Pueblo y Educación.

Nascimento, C. P. (2014). A atividade pedagógica da educação física: a proposição dos objetos de ensino e o desenvolvimento das atividades da cultura corporal. Tese de Doutorado, Faculdade de Educação. Universidade de São Paulo, São Paulo.

Rigon, A. J.; Asbahr, F. S. F.; Moretti, V. D. (2010). Sobre o processo de humanização. In: Moura, M. O. (Org.). A atividade pedagógica na teoria Histórico-Cultural. (pp. 13-44). Brasília: Liber livro.

Saviani, D. (2002). Educação: do senso comum à consciência filosófica. São Paulo: Autores Associados.

Sekkel, M. C. (2003). A construção de um ambiente inclusivo na educação infantil: relato e reflexão sobre uma experiência. Tese de Doutorado, Instituto de Psicologia. Universidade de São Paulo, São Paulo.

Vigotski, L. S. (2004). O significado histórico da crise da Psicologia. Uma investigação metodológica. In: Vigotski, L. S., Teoria e método em Psicologia. São Paulo: Martins Fontes.

Vygotski, L. S. (2001). Obras escogidas. Tomo II. Madrid: Visor.

Vygotski, L. S. (2006). Obras escogidas. Tomo IV. Madrid: A. Machado Libros.

Vigotski, L. S. (2010). Psicologia Pedagógica. São Paulo: Editora WMF Martins Fontes.

(cc) EY License information: This is an open-access article distributed under the terms of the License (type CC-BY), which permits unrestricted use, distribution and reproduction in any medium, provided the original article is properly cited. 